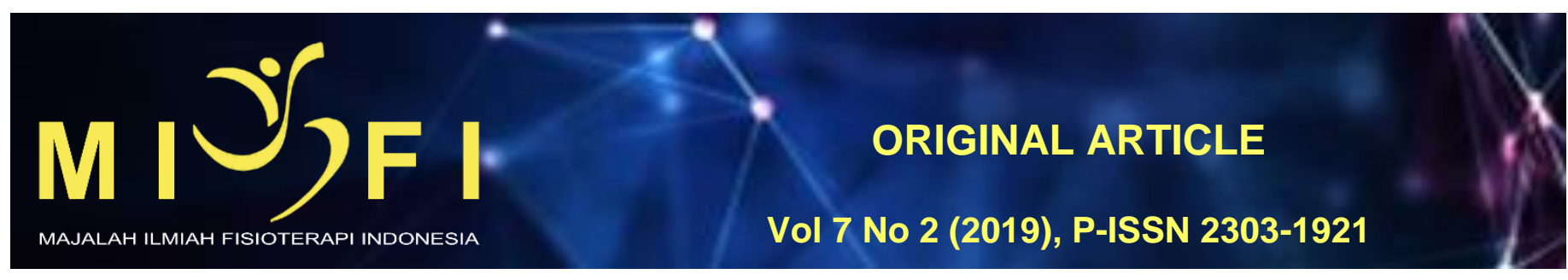

PENGARUH DURASI PENGGUNAAN DAN TINGKAT KECANDUAN SMARTPHONE TERHADAP KEJADIAN FORWARD SHOULDER POSTURE PADA REMAJA USIA 16-18 TAHUN DI SMA NEGERI 2 DENPASAR

\author{
Diana Putri Maharani ${ }^{1}$, Anak Ayu Nyoman Trisna Narta Dewi ${ }^{2}$, Ni Nyoman Ayu Dewi ${ }^{3}$ \\ ${ }^{1}$ Program Studi Fisioterapi dan Profesi Fisioterapi Fakultas Kedokteran Universitas Udayana \\ ${ }^{2}$ Departemen Fisioterapi Fakultas Kedokteran Universitas Udayana \\ 3Departemen Biokimia, Fakultas Kedokteran Universitas Udayana \\ dianapmaharani@gmail.com
}

\begin{abstract}
ABSTRAK
Penggunaan smartphone yang semakin meningkat dan dalam waktu yang lama dapat menyebabkan timbulnya gangguan muskuloskeletal, salah satunya Forward Shoulder Posture (FSP) apabila seseorang menggunakan smartphone dalam posisi yang tidak benar dalam waktu lama dan berulang. Durasi penggunaan smartphone dan tingkat kecanduan smartphone merupakan faktor penyebab terjadinya beberapa gangguan muskuloskeletal yang sering muncul. Penelitian berikut penelitian observasional analitik cross sectional dengan sampel remaja usia 16-18 tahun di SMA Negeri 2 Denpasar sejumlah 63 orang. Hasil diketahui durasi penggunaan smartphone memiliki efek signifikan pada kejadian FSP, $p$ sebesar $0,028(\mathrm{p}<0,05)$ serta tingkat kecanduan smartphone terdapat efek terhadap kejadian FSP, $p$ sebesar $0,043(p<0,05)$. Hasil regresi logistik, durasi penggunaan smartphone dan tingkat kecanduan smartphone merupakan faktor-faktor yang memengaruhi kejadian FSP pada remaja usia 16-18 tahun di SMA Negeri 2 Denpasar
\end{abstract}

Kata kunci: durasi penggunaan smartphone, tingkat kecanduan smartphone, forward shoulder posture

\title{
THE EFFECT OF DURATION OF SMARTPHONE USAGE AND LEVEL OF SMARTPHONE ADDICTION ON FORWARD SHOULDER POSTURE IN TEENAGERS AGED 16-18 YEARS IN SMA NEGERI 2 DENPASAR
}

Increased and prolonged use of smartphones may cause musculoskeletal disorders, one of which is Forward Shoulder Posture (FSP) if a person is using smartphone in an incorrectly position, long duration and repetitive position. The duration of smartphone usage and the level of smartphone addiction are a contributing factor to the occurrence of some frequent musculoskeletal disorders. The following research is cross sectional analytic observational research with sample of adolescent age 16-18 year in SMA Negeri 2 Denpasar 63 people. The result is known that the duration of smartphone usage has a significant effect on the FSP incidence, $p$ is $0.028(p<0,05)$ and the rate of smartphone addiction have an effect on the occurrence of FSP, $p$ equal to $0,043(p<0,05)$. Logistic regression results, the duration of smartphone use and the level of smartphone addiction are the factors that affect the incidence of FSP in adolescents aged 16-18 years in SMA Negeri 2 Denpasar

Keywords: duration of smartphone usage, level of smartphone addiction, forward shoulder posture

\section{PENDAHULUAN}

Pengguna smartphone semakin meningkat di berbagai belahan dunia1. Smartphone saat ini merupakan teknologi yang tidak dapat dipisahkan dari kehidupan manusia ${ }^{2}$. Sebagian besar pengguna smartphone adalah remaja. Sebanyak 79,5\% remaja di beberapa kota besar di Indonesia merupakan pengguna internet dan sebanyak $21 \%$ diakses melalui smartphone 3 . Semakin canggihnya smart-phone membuat durasi penggunaannya semakin meningkat. Durasi penggunaan smartphone dibagi menjadi 3 kategori, yaitu high duration atau pemakaian selama $<10$ menit/hari, medium duration atau pemakaian selama 20 menit/hari, serta high duration atau pemakaian selama $>30$ menit/hari ${ }^{4}$. Penilitian mengatakan bahwa durasi penggunaan smartphone pada remaja lebih tinggi dibandingkan dengan orang dewasa ${ }^{5}$. Remaja biasa menghabiskan sekitar 193,64 menit per hari ketika menggunakan smartphone ${ }^{5}$.

Durasi penggunaan smartphone yang tinggi dapat menyebabkan seseorang menjadi kecanduan smartphone ${ }^{6}$. Hasil penelitian mengungkapkan bahwa remaja sangat rentan untuk kecanduan dalam penggunaan smartphone. Kecanduan smartphone dapat diukur menggunakan Smartphone Addiction Scale-Short Version dengan menjumlahkan skor dari 33 pertanyaan?. Skor SAS-SV yang menunjukkan $\geq 84$ dikategorikan seseorang tersebut kecanduan smartphone ${ }^{8}$.

Penggunaan smartphone yang berulang dan berkepanjangan dapat berdampak negatif bagi tubuh manusia ${ }^{9}$. Manusia cenderung menggunakan smartphone dengan posisi yang cenderung forward seperti kepala bergerak forward (ke depan), memegang smartphone di dekat pinggang ketika duduk, melihat ke bawah dan menahan lengan di depan untuk membaca layar smartphone sehingga kelelahan serta sekit di leher dan bahu pun terjadi ${ }^{10}$. Forward Shoulder Posture (FSP) merupakan salah satu faktor resiko terjadinya gangguan muskuloskeletal di bagian bahu. FSP merupakan gerakan abduksi dan elevasi dari skapula dan pergerakan bahu ke arah depan ${ }^{11}$. FSP juga disebabkan terjadi pemendekan pada otot anterior shoulder grain, seperti serratus anterior dan pectoralis minor serta terjadi 
lemahnya otot yang berfungsi menarik skapula ke belakang seperti otot rhomboid dan middle trapezius. FSP dapat diperiksa menggunakan teknik Acromion Table-Distance (AT-Distance) dengan cara mengukur jarak antara posterior border dari acromion dan meja secara vertikal ketika subjek tidur terlentang di atas meja dengan tangan yang rileks disamping badan ${ }^{12}$. Hasil pengukuran dikatakan positif FSP apabila mendapatkan hasil $>2,5 \mathrm{~cm}^{13}$.

Meningkatnya durasi pemakaian dan tingkat kecanduan smartphone menyebabkan postur tubuh bagian atas seperti bahu cenderung selalu bergerak ke arah depan (forward). Hal ini dapat menyebabkan pengguna smartphone mengalami FSP. Penelitian ini ingin mengetahui adanya pengaruh antara durasi penggunaan dan tingkat kecanduan smartphone terhadap kejadian FSP.

\section{METODE}

Penelitian berikut merupakan penelitian observasional analitik dengan menggunakan pendekatan cross sectional dilaksanakan bulan Maret 2018 di SMA Negeri 2 Denpasar. Sampel penelitian diambil sebanyak 63 orang yang dipilih menggunakan teknik simple random sampling dan telah disesuaikan dengan kriteria inklusi serta kriteria eksklusi. Sampel mengisi kuisioner data penggunaan smartphone untuk mengetahui durasi penggunaan smartphone dan kuisioner Smartphone Addiction Scale-Short Version (SAS-SV) untuk mengetahui tingkat kecanduan smartphone. Pengukuran FSP pada sampel dilakukan dengan teknik Acromion Table-Distance (AT-distance). Hasil penelitian didapatkan dengan analisis bivariat uji chi-square dan analisis multivariat uji regresi logistik.

\section{HASIL}

Sampel berjumlah 63 orang dengan rincian 39 orang $(61,9 \%)$ berjenis kelamin perempuan dan 24 orang $(38,1 \%)$ berjenis kelamin laki-laki. Usia 16 tahun merupakan usia terbanyak yaitu sebanyak 27 orang (42,9\%), diikuti usia 18 tahun sebanyak 21 orang (33,3\%), dan usia 17 sebanyak 15 orang $(23,8 \%)$.

Sebanyak 31 orang $(49,2 \%)$ menggunakan smartphone dengan durasi high, sebanyak 32 orang (50,8) menggunakan smartphone dengan durasi medium, sedangkan tidak ada satupun sampel yang menggunakan smartphone dengan durasi low. Sebanyak 26 orang (41,3\%) dikategorikan kecanduan smartphone dan sebanyak 37 orng $(58,7 \%)$ dikategorikan tidak kecanduan smartphone. Menurut hasil pengukuran FSP, sebanyak 46 orang (73\%) positif FSP dan sebanyak 17 orang (27\%) negatif FSP.

Tabel 1. Karakteristik Sampel

\begin{tabular}{|c|c|c|}
\hline Variabel & $\mathbf{F}$ & $\%$ \\
\hline \multicolumn{3}{|l|}{ Umur } \\
\hline 16 & 27 & 42,9 \\
\hline 17 & 15 & 23,8 \\
\hline 18 & 21 & 33,3 \\
\hline \multicolumn{3}{|l|}{ Jenis Kelamin } \\
\hline Perempuan & 39 & 61,9 \\
\hline Laki-laki & 24 & 38,1 \\
\hline \multicolumn{3}{|c|}{ Durasi Penggunaan Smartphone } \\
\hline Low & 0 & 0 \\
\hline Medium & 32 & 50,8 \\
\hline High & 31 & 49,2 \\
\hline \multicolumn{3}{|c|}{ Tingkat Kecanduan Smartphone } \\
\hline Kecanduan & 26 & 41,3 \\
\hline Tidak Kecanduan & 37 & 58,7 \\
\hline \multicolumn{3}{|c|}{ Forward Shoulder Posture } \\
\hline Positif & 46 & 73 \\
\hline Negatif & 17 & 27 \\
\hline
\end{tabular}

Pengujian hipotesis mengguna-kan uji chi square pada Tabel 2. Setelah dilakukan pengujian efek durasi penggunaan smartphone terhadap kejadian FSP, nilai $p$ sebesar $0,028(p<0,05)$. Hasil dapat dikatakan terdapat efek signifikan dari durasi penggunaan smartphone terhadap kejadian FSP. Sedangkan pengujian efek tingkat kecanduan smartphone pada kejadian FSP, didapatkan nilai $p$ sebesar $0,043(p<0,05)$ yang menunjukkan terdapat efek signifikan dari tingkat kecanduan smartphone terhadap kejadian FSP.

Tabel 2. Uji Chi-square

\begin{tabular}{|c|c|c|c|c|c|}
\hline \multicolumn{6}{|c|}{ Durasi Penggunaan Smartphone } \\
\hline & \multicolumn{2}{|c|}{ Positif FSP } & \multicolumn{2}{|c|}{ Negatif FSP } & \multirow{2}{*}{$\mathbf{p}$} \\
\hline & $\mathbf{n}$ & $\%$ & $\mathbf{n}$ & $\%$ & \\
\hline Medium & 19 & 59,4 & 13 & 40,6 & \\
\hline High & 27 & 87,1 & 4 & 12,9 & \\
\hline Total & 46 & 73,0 & 17 & 27,0 & 0,028 \\
\hline \multicolumn{6}{|c|}{ Tingkat Kecanduan Smartphone } \\
\hline & \multicolumn{2}{|c|}{ Positif FSP } & \multicolumn{2}{|c|}{ Negatif FSP } & \\
\hline & $\mathbf{n}$ & $\%$ & $\mathbf{n}$ & $\%$ & $\mathbf{p}$ \\
\hline Kecandu-an & 23 & 88,5 & 3 & 11,5 & \\
\hline Tidak & 23 & 62,2 & 14 & 37,8 & \\
\hline Total & 46 & 73,0 & 17 & 27,0 & 0,043 \\
\hline
\end{tabular}


Pada Tabel 3. merupakan hasil uji regresi logistik dimana untuk variabel durasi penggunaan smartphone nilai p sebesar 0,021 $(p<0,05)$ dimana bisa disimpulkan terdapat efek durasi penggunaan smartphone terhadap kejadian FSP. Sedangkan nilai Prevalence Ratio (PR) sebesar 0,212 yang berarti durasi penggunaan smartphone yang tinggi dapat meningkatkan resiko kejadian FSP 0,212 kali lebih tinggi dibandingan dengan durasi penggunaan smartphone yang rendah. Hasil uji untuk variabel tingkat kecanduan smartphone nilai $p$ sebesar $0,032(p<0,05)$, dapat disimpulkan adanya efek tingkat kecanduan smartphone terhadap kejadian FSP. Sedangkan nilai Prevalence Ratio (PR) sebesar 4,774 yang berarti tingkat kecanduan smartphone yang tinggi dapat meningkatkan resiko kejadian FSP 4,774 kali lebih tinggi dibandingkan dengan tingkat kecanduan smartphone.

Tabel 3. Uji Regresi Logistik

\begin{tabular}{ccc}
\hline Variabel & p & Prevalence Ratio \\
\hline Durasi Penggunaan Smartphone & 0,021 & 0,212 \\
Tingkat Kecanduan Smartphone & 0,032 & 4,774 \\
\hline
\end{tabular}

\section{DISKUSI}

Sampel sebanyak 63 orang merupakan siswa-siswi SMA Negeri 2 Denpasar berusia 16-18 tahun yang diambil secara acak dan telah disesuaikan dengan kriteria inklusi serta eksklusi. Usia 16-18 tahun dikategorikan sebagai remaja sejati ${ }^{14}$. Usia remaja memiliki pengaruh terhadap penggunaan smartphone.

Durasi penggunaan smartphone pada penelitian ini didapatkan hasil bahwa sebanyak 32 orang (50,8\%) menggunakan smartphone dengan durasi medium dan sisanya menggunakan smartphone dengan durasi high. Hasil ini menunjukkan bahwa penggunaan smartphone dengan durasi medium lebih banyak dibandingkan dengan durasi high. Hal ini didukung oleh penelitian Widhiyanto ${ }^{15}$ yang menyatakan bahwa tidak semua remaja menggunakan smartphone dengan durasi yang tinggi.

Tingkat kecanduan smartphone pada penelitian ini juga menunjukkan bahwa sebanyak 37 orang (58,7\%) dikategorikan tidak kecanduan sedangkan sisanya dikategorikan kecanduan smartphone. Sampel dengan kategori tidak kecanduan smartphone lebih banyak dibandingan dengan sampel yang mengalami kecanduan smartphone. Seperti halnya dengan durasi penggunaan smartphone, tidak semua remaja mengalami kecanduan terhadap smartphone ${ }^{15}$. Remaja yang tidak mengalami kecanduan smartphone biasanya lebih memilih untuk berinteraksi terhadap lingkungan sosialnya, melakukan kegiatan ekstra kurikuler, dan masih banyak penyebab lainnya ${ }^{15}$.

Pengujian melalui uji chi-square, didapatkan nilai $p$ sebesar $0,028(p<0,05)$ di mana bisa disimpulkan adanya hubungan signifikan durasi penggunaan smartphone dan FSP. Hal ini dapat disebabkan karena kurangnya fokus dalam memperhatikan posisi penggunaan smartphone, membuat pengguna smartphone cenderung menggunakan smartphone pada posisi yang cenderung forward (ke depan) ${ }^{16}$. Penggunaan smartphone dalam durasi yang lama dan dengan posisi yang cenderung forward (ke depan) dapat meningkatkan resiko terjadinya FSP. Tidak semua sampel mengamalami FSP meskipun menggunakan smartphone dengan durasi yang lama. Adanya faktor seperti menggunakan smartphone pada posisi yang benar menyebabkan tidak terjadinya FSP meskipun menggunakan smartphone dengan durasi yang tinggi ${ }^{15}$.

Uji chi square kedua nilai p sebesar 0,043 $(p<0,05)$ berarti terdapat hubungan signifikan tingkat kecanduan smartphone dan FSP. Kecanduan smartphone menyebabkan seseorang cenderung untuk menggunakan smartphone secara terus-menerus. Penggunaan smartphone secara terus-menerus dalam posisi yang non-neutral dapat menyebabkan FSP. Kecanduan smartphone dapat dinilai juga dari durasi penggunaan smartphone, sehingga menyebabkan sampel yang dikategorikan kecanduan smartphone dapat terkena FSP apabila menggunakan smartphone dengan durasi yang tinggi6.

Uji regresi logistik didapatkan hasil untuk durasi penggunaan smartphone yaitu $E x p=0,212$ dan nilai $p=0,021$ $(p<0,05)$ yang berarti durasi penggunaan smartphone yang tinggi dapat mengakibatkan tingginya resiko FSP 0,212 kali dibandingkan dengan durasi penggunaan smartphone yang rendah. Sedangkan untuk tingkat kecanduan smartphone didapatkan hasil Exp $B=4,774$ dan nilai $p$ sebesar $0,032(p<0,05)$, bisa disimpulkan tingkat kecanduan smartphone tinggi dapat mengakibatkan tingginya resiko FSP 4,774 kali dibandingkan dengan tingkat kecanduan smartphone yang rendah.

Penyebab utama terjadinya forward posture adalah dikarenakan buruknya posisi tubuh saat melakukan aktivitas $^{5}$. Kurangnya fokus dalam memperhatikan posisi penggunaan smartphone, membuat pengguna smartphone cenderung menggunakan smartphone pada posisi yang non-neutral ${ }^{16}$. Apabila seseorang menggunakan smartphone dalam waktu yang lama dan dikategorikan kecanduan smartphone, maka orang tersebut akan menggunakan smartphone secara berkepanjangan dan berulang. Apabila postur tubuh dalam menggunakan smartphone tidak benar dalam waktu yang lama dan berulang, maka dapat menyebabkan dampak negatif pada tubuh, seperti meningkatkan sudut leher yang dapat menyebabkan FHP dan juga dapat menyebabkan FSP.

\section{SIMPULAN}

Berdasarkan hasil penelitian dan diskusi, dapat ditarik beberapa kesimpulan antara lain, (1)Durasi penggunaan smartphone berpengaruh terhadap kejadian FSP (2)Tingkat kecanduan smartphone memiliki pengaruh pada kejadian FSP (3)Durasi penggunaan smartphone dan tingkat kecanduan smartphone merupakan faktor-faktor yang berpengaruh terhadap kejadian FSP pada remaja usia 16-18 tahun di SMA Negeri 2 Denpasar.

\section{DAFTAR PUSTAKA}

1. White, J., \& Mills, D. J. (2015). Examining Attitudes towards and Usage of Smartphone Technology among Japanese University Students Studying EFL. CALL-EJ , 15 (2), 1-15. 
2. Choi, N. (2015). The Effects of a Smartphone Addiction Education Program for Young Adult Females. International Journal of $u$ - and e- Service, Science and Technology , 8 (12), 277-284.

3. Gayatri, G., Rusadi, U., Meiningsih, S., Dede, M., Sari, D., Kautsarina, et al. (2015). Perlindungan Pengguna Media Digital di Kalangan Anak dan Remaja di Indonesia. Jurnal Penelitian dan Pengembangan Komunikasi dan Informatika, 6 (1), 1-16.

4. Kim, S.-Y., \& Koo, S.-J. (2016). Effect of Duration of Smartphone Use on Muscle Fatigue and Pain Caused by Forward Head Posture in Adults. J. Phys. Ther. Sci. , 28 (6), 1669-1672.

5. Markowetz, A., \& Montag, C. (2016). How Age and Gender Affect Smartphone Usage. Heidelberg: UbiComp.

6. Goswami, V., \& Singht, D. R. (2015). Impact of Mobile Phone Addiction on Adolescent's Life: A Literature Review. International Journal of Home Science , 2 (1), 69-74.

7. Kwon, M., Kim, D.-J., Cho, H., \& Yang, S. (2013). The Smartphone Addiction Scale: Development and Validation of a Short Version for Adolescents. PLOS One, VIII (12), 1-7.

8. Inal, E. E., Demirci, K., Cetinturk, A., Akgonul, M., \& Savas, S. (2015). Effects of Smartphone Overuse on Hand Function, Pinch Strength, and the Median Nerve: Smartphone Overuse. Muscle Nerve, 52, 183-188.

9. Lee, S.-Y., Lee, D.-H., \& Han, S.-K. (2016). The Effects of Posture on Neck Flexion Angle While Using a Smartphone According to Duration. J Korean Soc Phys Med , 11 (3), 35-39.

10. Moawd, S. A., \& Ali, S. E. (2015). Effect of Over-Usage of Smart Phone in a Non-Neutral Neck Position on Respiratory Function in Female Adults. International Journal of Therapies and Rehabilitation Research , 4 (4), 104110.

11. Ghanbari, A., Farahnaz, G., Farshid, M., \& Shobani, S. (2008). Effect of Forward Shoulder Posture on Pulmonary Capacities of Women. British Journal of Sports Medicine , 42 (7), 622-623.

12. Struyf, F., Roussel, N., Cools, A., \& Meeusen, R. (2012). Clinical Assessment of The Scapula: A Review of The Literature. British Journal of Sports Medicine, 1-8.

13. Kim, T.-W., An, D.-I., Lee, H.-Y., Jeong, H.-Y., Kim, D.-H., \& Sung, Y.-H. (2016). Effects of Elastic Band Exercise on Subjects with Rounded Shoulder Posture and Forward Head Posture. The Journal of Physical Therapy Science , 28 (6), 1733-1737.

14. Ratnasari, M. (2012). Perkembangan Kepribadian pada Tokoh Utama dalam Novelet Babalik Pikir Karya Samsoedi. Jurnal Universitas Padjadjaran.

15. Widhiyanto, A., Munawir, A., \& Prayitno, H. (2017). The Effect of Duration of Smartphone Usage on Neck Pain. Dama International Journal of Researchers , 2 (11), 54-61.

16. Minter, T. (2013). Ergonomics \& The Mobile Environment. 24-27. 